\title{
Comportamento do consumidor nova-pratense para compras em ambientes físicos ou virtuais
}

\author{
Rosecler Maschio Gilioli Doutora em Administração. Universidade de Caxias do Sul (UCS) Brasil - rgilioli@terra.com.br \\ Daiane Roncato Bacharel em Administração. Universidade de Caxias do Sul (UCS) Brasil - dai_roncato@hotmail.com
}

\begin{abstract}
RESUMO
O tema trata sobre o comportamento do consumidor nova-pratense, que efetua compras físicas e/ou virtuais com o propósito de poder identificar seu perfil, os produtos e o que o leva a adquirir esses produtos de forma física e/ou virtual, por meio de entrevistas com empresas sobre o comportamento desse consumidor e aplicação de questionários à população. Por fim, criar recomendações aos lojistas de Nova Prata a partir da análise e identificação dos resultados propostos anteriormente. O método adotado é de natureza qualitativa, de nível exploratório com estudo de caso quando tratado das entrevistas com as empresas participantes do estudo e quantitativa, de nível descritivo e aplicação de estratégia survey para a análise e apreciação das informações obtidas através da coleta de dados da pesquisa com a maior amostra possível de consumidores residentes em Nova Prata/RS.
\end{abstract}

Palavras-chave: Consumidor. Logística. Loja Virtual.

\section{Behavior of the Nova Prata consumer for purchases in physicals or virtual environment}

\begin{abstract}
The theme of this s study is about the behavior of consumers in Nova Prata, concerning their purchases in physical and/or virtual environments, in order to identify their profiles, the products they buy and what leads them to acquire these products either way. The investigation made use of interviews with companies on the behavior of the consumers and as well as the application of questionnaires to the population. Another aim of this study was to make recommendations to the shopkeepers of Nova Prata based on the analysis and identification of the results proposed previously. The method adopted is of a qualitative nature, of exploratory level with a case study when dealing with interviews with the companies participating in the study, and quantitative, descriptive, and with application of a survey strategy for the analysis and appreciation of the information obtained through the collection of data from largest possible sample of consumers residing in Nova Prata / RS.
\end{abstract}

Keywords: Consumer. Physical trade. Virtual trade. 


\section{INTRODUÇÃO}

O presente artigo foi elaborado abordando o tema comportamento do consumidor nova-pratense, que efetua compras físicas e/ou virtuais.

Para as organizações o tema se torna relevante quando analisadas as possibilidades geradas para compreender o comportamento de compra e como estar mais preparado e alinhado com essa realidade e melhor atender e ampliar a proximidade com seus consumidores. Schweriner (2006) defende que de certo modo o consumo acelerado é bem-vindo para as empresas que desejam estar alinhadas com as situações econômicas por intermédio da propaganda, assim os produtos se tornam desejáveis, sedutores, quando não imprescindíveis ao consumidor. Tornando-se cada vez mais presentes na rotina dos consumidores possibilita o pleno uso da capacidade de produção das empresas, permitindo inclusive sua constante ampliação. Esses fatores permitem gerar consequências positivas como o aumento do lucro e o índice de empregos.

Para Rocha (2009) possuir conhecimento sobre a cadeia de consumo permite que as organizações analisem onde estão mais preparadas para se diferenciar da concorrência.

A metodologia adotada teve seu escopo qualitativo, de nível exploratório com estudo de caso quando abordado sobre as três empresas participantes do estudo e de escopo quantitativo, de nível descritivo, e aplicação de estratégia survey quando da interpretação dos dados coletados a partir de pesquisa estruturada com a maior amostra possível de consumidores residentes em Nova Prata/RS.

Foram realizadas, por meio de instrumento de coleta de dados, entrevistas e após o desenvolvimento destas os principais resultados identificados apontaram que compreender que o comércio eletrônico e o uso da tecnologia vêm afetando e se tornando cada vez mais usual na vida do consumidor. Permitiu-se concluir que há grande retorno dos clientes que estão na loja física por terem visualizado as divulgações on-line; no entanto, concluiu-se também, que ainda há receio quanto ao uso do comércio eletrônico, mas este pode se tornar preferencial pelos preços e descontos oferecidos. De modo geral, identificou-se forte tendência de realização de compras a prazo, seja pelo uso do cartão de crédito ou pelo próprio crediário oferecido pelas lojas.

No comércio físico, os descontos, o pagamento parcelado e sem juros, ou o maior prazo para pagamento foram indicados na opinião dos entrevistados, e duas das lojas afirmaram que o próprio atendimento dos vendedores é fator relevante e, muitas vezes, decisivo para a compra. Mencionou-se inclusive que um mau atendimento pode gerar perda de venda ou até mesmo de cliente e acreditam ser um fator de forte relevância para o consumidor.

Após as entrevistas foi elaborado um questionário contendo vinte e uma questões de múltipla escolha e uma questão final aberta para comentários e sugestões que tinha como objetivo identificar sexo, idade, profissão, estado civil, escolaridade e renda familiar, produtos comprados e os motivos que levaram os consumidores nova-pratenses a efetuarem compras de forma virtual e no comércio da cidade.

Na etapa seguinte foi realizado pré-teste com três pessoas, o que permitiu analisar a clareza e a coerência das questões, sendo após essa análise propostas alterações na forma que algumas questões foram escritas; alterações estas realizadas antes da distribuição para a amostragem maior dos participantes da pesquisa. $O$ plano de amostragem adotado foi pela maior quantidade possível de pessoas que se disponibilizaram a responder o questionário, desde que tivessem mais de 14 anos de idade e residissem em Nova Prata.

O método de contato foi feito por meio de entrevistas pessoais e questionário on-line em virtude da possibilidade de abranger maior diversidade populacional, sendo aplicados no período de sete a vinte e três de setembro de 2016. A quantidade mínima de questionários pelo método Hair Junior et al. (2005), adotado nesse trabalho foi de 220 formulários. Foram distribuídos de forma eletrônica e por meio de entrevistas pessoais trezentos e vinte e nove questionários, sendo desses respondidos cento e quarenta e oito questionários válidos.

Os resultados da aplicação da pesquisa foram apresentados por meio de tabelas, obtendo-se como perfil a maioria representada por consumidores do sexo feminino, com idade entre trinta e um a quarenta anos, trabalhadores da área da indústria, casados, possuidores de formação superior completa e com renda familiar média mensal de quatro a seis salários mínimos.

Os produtos mais adquiridos de forma física e virtual apontaram: para o comércio físico as compras de alimentos e bebidas e artigos de vestuários e acessórios e para o comércio eletrônico equipamentos eletrônicos e em sequência artigos de vestuário e acessórios.

Foram apontados como principais motivos que levam o consumidor que reside em Nova Prata a adquirir produtos no comércio físico é a possibilidade de ter maior contato e sair do comércio com o produto, seguido pelas promoções e descontos e os pagamentos parcelados e sem juros. O cartão de crédito e dinheiro foram apontados como sendo as principais formas de pagamento adotadas pelos consumidores. No comércio eletrônico, os preços 
diferenciados e a diversidade oferecida apontam a preferência, porém há o medo de fraudes por sitesfalsos e o receio quanto à qualidade e definições do produto que acabam reduzindo a confiança dos consumidores. As promoções mais apontadas foram os descontos e a oferta de frete grátis, paralelo ao uso do cartão de crédito como meio principal de pagamento e a preferência por pagar suas compras a prazo.

\section{REFERENCIAL TEÓRICO}

Neste capítulo será tratado sobre o comportamento do consumidor, compras físicas e conceito de $e$ commerce.

\subsection{Comportamento do consumidor}

Nesta seção serão expostos conceitos do comportamento do consumidor. De acordo com Solomon (2011), deve-se observar que na medida em que os consumidores adquirem produtos ou serviços eles buscam satisfazer suas necessidades, levando-se em conta que em determinados momentos desempenham diferentes papéis, onde o comprador e o usuário do produto podem não ser a mesma pessoa, como quando um pai ou uma mãe compra roupas para um filho adolescente. Cada vez que o consumidor assume um papel diferente, seu comportamento de compra também será diferente, pois em cada momento estará representando diferentes necessidades.

Já Peter e Olson (2010) trazem a abordagem de que o comportamento do consumidor envolve os pensamentos e os sentimentos experimentados pelas pessoas e as ações que geram sobre o processo de consumo, incluindo também todas as coisas que constam no ambiente que podem influenciar esse pensamento, sentimentos e ações, podem influenciar: os comentários de outras pessoas, propagandas, preço, embalagem, aparência do produto e muitos outros. Notando-se que o comportamento do consumidor é dinâmico e envolve interações e trocas.

No ponto de vista de Hawkins, Mothersbaugh e Best (2007) o campo do comportamento do consumidor envolve indivíduos, grupos ou organizações e a seleção que fazem a fim de obter, usar e dispor de produtos, serviços, experiências ou ideias visando satisfazer suas necessidades e o impacto que esses processos têm sobre si mesmos e sobre a sociedade. É também ressaltado pelos autores que entender e interpretar adequadamente as vontades dos consumidores se torna bem mais complicado na prática e que semanalmente os pesquisadores de marketing conversam com mais de quatro mil consumidores a fim de descobrir: o que pensam sobre os produtos e os produtos dos concorrentes, o que pensam sobre possíveis melhorias dos produtos, como usam os produtos, que atitude possuem sobre o produto e a propaganda, o que pensam sobre seu papel e de sua família na sociedade e quais são os sonhos para si mesmos e para suas famílias. Sendo, mais do que nunca, incerto realizar negócios hoje, por isso se torna necessário entender e, portanto, antecipar o comportamento do consumidor, planejar e gerenciar nesse ambiente em constante mudança.

Sendo assim, o comportamento de compra do consumidor sofre influências de muitos fatores que direta e indiretamente contribuem para sua decisão de compra. Esse entendimento também colabora para que os profissionais de marketing possam moldar suas estratégias de trabalho e alcancem seus objetivos, podendo inclusive estar mais atentos às necessidades lançadas pela sociedade conseguindo compreendê-la e satisfazê-la na sua grande maioria.

\subsection{Conceito de compras físicas}

Mencionando o que foi exposto anteriormente, as compras físicas são aquelas que são efetuadas por intermédio do ambiente físico, que é o espaço propriamente disponível pelo vendedor para receber seus clientes.

Moura (2014) ressalta que a loja física proporciona ao cliente a possibilidade de transitar entre várias, observando e coletando informações do produto ou serviço, sendo que também deve estar bem localizada e acessível, ser reconhecida pela comunidade onde está inserida e os concorrentes diretos e indiretos na região.

De forma complementar, Solomon (2011) fala que a experiência de compra é uma parte central da decisão sendo o conjunto da loja (vendedores, disposição de materiais, ambiente, acessórios, imagem da loja e personalidade da marca) influenciadores na avaliação do cliente. A crescente concorrência de alternativas fora da loja exige que a experiência de compras seja a mais positiva possível. 
Já De Angelo e Giangrande (2007), relatam que dentro do contexto do mercado varejista brasileiro o grande diferencial, que irá definir quais varejistas terão sucesso e quais irão fracassar, será a capacidade de entender, atrair e satisfazer os consumidores.

Percebe-se dessa forma que o ambiente físico é a estrutura disponível para que o consumidor ao acessar possa visualizar, tocar, provar e tirar experiências positivas dos produtos para que a compra que efetuar satisfaça seus desejos e intenções. Avaliando as citações apresentadas, compreende-se que essa estrutura de comércio permanece atuante nas escolhas de compra dos consumidores, pois dentre vários fatores, ainda permite uma aproximação do cliente com o seu objeto de consumo. A seguir serão expostas comparações com o comércio eletrônico, podendo-se ao final realizar a comparação de como esse modelo está situado dentro do cenário de consumo moderno.

\subsection{Conceito de e-commerce}

Para estas compreensões serão abordados os conceitos do e-commerce, ou comércio eletrônico (CE) e suas categorias.

Turban e King (2004) tratam do comércio eletrônico como o processo de compra, venda e troca de produtos, serviços e informações por redes de computadores ou internet. O termo comércio para muitos é tratado apenas como transações efetuadas entre parceiros de negócio, se tornando um pouco restrita, podendo-se então denominar $e$ business, pois carrega na sua definição, além de compra e venda de produtos ou serviços, também a prestação de serviços a clientes, cooperação com parceiros comerciais e a realização de negócios eletrônicos dentro de uma organização.

Para Teixeira (2015) o comércio eletrônico ou e-commerce representa parte do presente e do futuro do comércio, permitindo que além dos muitos negócios que já existem, muitos outros vão sendo criados a todo o momento.

Concluindo que o comércio eletrônico é uma extensão do comércio convencional por se tratar de um ambiente digital de operações de troca, compra, venda e prestações de serviços auxiliadas pelo suporte de programas e equipamentos de informática permitindo que se consiga realizar a negociação.

No aspecto do conceito de comércio eletrônico nota-se que o avanço tecnológico possibilitou que houvesse uma expansão muito grande no consumo on-line, pois permitiu atingir um grande número de pessoas, que diariamente estão conectadas à rede mundial de computadores. Em seguida, será abordada a importância de cada tipo de comércio e comparações que permitem possuir uma maior clareza sobre seus aspectos no cenário do comércio atual.

\section{MÉTODO DE PESQUISA}

Considerando que o objetivo dessa abordagem é poder analisar os conceitos acerca do comportamento de compra do consumidor físico e on-line e o conjunto de fatores que fundamentam esse comportamento, foi desenvolvida uma pesquisa de natureza qualitativa, de nível exploratório, com estudo de caso na abordagem das empresas-alvos e quantitativa, de nível descritivo e aplicação de estratégia surveyquando da interpretação dos dados coletados a partir de pesquisa estruturada com a maior amostra possível de consumidores residentes em Nova Prata/RS.

\subsection{Escopo qualitativo}

Aqui, são apresentados conceitos sobre natureza qualitativa, nível exploratório, processo de coleta de dados com entrevistas semiestruturadas, processo de coleta e análise de dados.

\subsubsection{Natureza qualitativa}

Staw (1977 apud ROESCH, 2005) esclarece que a pesquisa qualitativa e seus métodos de coleta e análise de dados são mais adequados para uma fase exploratória da pesquisa sendo mais apropriada para a avaliação formativa visando melhorar a efetividade de programas ou planos.

Dessa forma, a pesquisa qualitativa, partindo do pressuposto de que se enquadra melhor quando há a intenção de melhorar um programa ou um plano, será utilizada nessa etapa, onde haverá a compreensão da situação 
das empresas-alvos para que a partir desse entendimento, se comparando com os resultados da pesquisa de mercado permitirá que esses gestores possam ter clareza dos fatores situacionais que estão cooperando nas influências e decisões de compra de seus clientes.

Com isso também se conseguirá perceber que a pesquisa é voltada para a organização com a finalidade de observar dados e amostragens referentes a uma situação estudo, onde há a intenção de se alcançar uma análise e, assim, poder agir sobre ela.

\subsubsection{Nível exploratório}

Para a fase da divisão dos níveis da pesquisa qualitativa, será considerado o nível exploratório para utilização nesse estudo, sendo apresentado no decorrer dessa seção.

Gil (2008) conceitua a pesquisa como sendo um processo formal e sistemático para o desenvolvimento de um método científico, tendo como objetivo principal descobrir respostas para problemas, sendo adotados procedimentos científicos.

Ainda, conforme Gil (2008, p. 27) "As pesquisas exploratórias têm como propósito proporcionar maior familiaridade com o problema, com vistas a torná-lo mais explícito ou a construir hipóteses.", e segundo Roesch (2005, p. 155-156) o "modo exploratório visa levantar questões e hipóteses para futuros estudos, por meio de dados qualitativos".

Nessa abordagem será adotada a forma exploratória, podendo ser conceituada, ainda de acordo com o mesmo autor, como forma de desenvolver, esclarecer e modificar conceitos e ideias visando que haja a formulação de problemas mais precisos ou hipóteses viáveis para pesquisas posteriores. Envolvem costumeiramente levantamento bibliográfico e documental, entrevistas não padronizadas e estudo de caso. Outro objetivo dessa forma de pesquisa é proporcionar uma visão geral, muito embora aproximada, sobre determinado fato.

Nota-se que a pesquisa de nível exploratório permite que haja uma análise sobre fatos ou objetos de estudo para que se consiga aprofundar conhecimentos e desenvolver observações pertinentes dessas situações e que a somatória desse agregado de informações desencadeie um conjunto de interpretações pertinentes à análise, bem como para os próprios participantes do estudo de caso.

\subsubsection{Estratégia de estudo de caso}

Para essa compreensão será conceituada a estratégia de estudo de caso e sua aplicação dentro do contexto da estrutura da pesquisa adotada para esse estudo.

A abordagem de Gil (2010) traz que o estudo de caso é mais um modelo de delineamento, dentre outros, para a produção de conhecimento dentro do campo científico, traz uma abordagem flexível, mas que igualmente proporciona condições para a interpretação da situação-alvo, além de indicar princípios e regras a serem observados no decorrer da produção da pesquisa que envolve as etapas de formulação e delimitação do problema, seleção de amostragem, determinação dos procedimentos para coletar e analisar dados, bem como os modelos para que sejam interpretados.

Yin (1981 apud ROESCH, 2005) menciona que o estudo de caso é uma estratégia de pesquisa que permite analisar fenômenos contemporâneos também sendo adotado como modo exploratório, projetando levantar questões e hipóteses para estudos futuros por meio de dados qualitativos.

Compreende-se assim, que o estudo de caso é um método de pesquisa que permite através da seleção de uma amostragem determinada, coletar, analisar e relatar fatores que permitirão ser inseridos no contexto da abordagem de forma a agregar conteúdo e exemplos da realidade comparados ao estudo e ao objetivo pretendido com o estudo. Dessa forma, as empresas selecionadas como amostragem nessa pesquisa, apresentarão fatos, bem como dados da sua realidade, para que sejam relatados e explorados com mais detalhamento prevendo que se possa compreender sua relação com o comportamento do consumidor e sua inserção dentro do universo da tecnologia na abordagem de comércio virtual e físico.

\subsubsection{Processo de coleta de dados}

Cooper e Schindler (2011) afirmam que a entrevista é a técnica básica de coleta de dados em metodologias qualitativas alinhado com a entrevista não estruturada, onde não há nenhuma questão específica ou ordem de tópicos a serem discutidos, sendo cada entrevista customizada para cada participante. 
Já para Roesch (2005) o grau de estruturação de uma entrevista de pesquisa qualitativa é variável conforme o interesse e ideal do entrevistador. Considerando que há as entrevistas semiestruturadas, que são compostas por questões previamente elaboradas, mas abertas permitindo que a entrevista consiga ter uma direção a seguir e as entrevistas totalmente sem estrutura, onde o entrevistado fala de forma livre e consecutiva que muitas vezes podem fornecer informações com pouca conexão ou difíceis de analisar. Dessa forma, recomenda-se que o ideal é possuir ao menos uma lista de tópicos para que a pesquisa seja conduzida e que cheguem ao ponto de interesse do pesquisador.

Dessa forma, para essa análise, será adotada a forma de pesquisas semiestruturadas, onde através de um roteiro de perguntas previamente elaborado, serão coletados dados e assuntos das empresas em questão.

As questões irão permitir que seja seguido um roteiro semelhante às que serão aplicadas posteriormente para a maior amostragem possível de moradores de Nova Prata. A semelhança de roteiro de entrevista permitirá que os dados sejam próximos e mais coerentes para parâmetros de comparação na análise dos mesmos no decorrer desse estudo.

As entrevistas semiestruturadas com gestores das três empresas-alvos permitirão que sejam alcançadas percepções de consumo e situações que interagem e refletem as decisões finais de compra de seus clientes, bem como sua visão estratégica de negócio estando este inserido dentro do contexto atual de cenário econômico e tecnológico.

Nota-se para tanto, que o processo de coleta de dados, permite que a pesquisa possua fontes verídicas, que embasadas com o conteúdo científico, possam representar à população conhecimento sobre a situação e estrutura que as empresas estão modeladas dentro de uma perspectiva de comparação com o comportamento do consumidor.

\subsubsection{Processo de análise de dados}

Ainda de acordo com Roesch (2005), ao final da coleta de dados, o entrevistador se depara com uma grande quantidade de informações, notas de pesquisa ou depoimentos, materializados em forma de texto, que deverão ser estruturados para posteriormente serem analisados. Muito embora, historicamente, os pesquisadores venham adotando esse processo através da análise quantitativa, sendo que esta tem o propósito de contar a frequência de um fenômeno e procurar identificar sua relação com demais fenômenos.

Para Marconi e Lakatos (1999) no processo de análise dos dados é feita uma análise mais detalhada sobre os dados levantados, a fim de conseguir respostas as suas indagações, procurando estabelecer as relações necessárias entre os dados obtidos e as hipóteses formuladas e estas são comprovadas ou rejeitadas, mediante a análise.

Para Roesch (2005) a análise de discurso consiste em analisar a estrutura de um texto, e a partir disto averiguar as construções ideológicas presentes no momento. Segundo os analistas de discurso, a linguagem não é um meio de refletir a realidade de forma não problemática, mas desempenha um papel ativo na construção da realidade, portanto é essencial verificar como e quando a variação no discurso surge e para que serve.

\subsection{Escopo Quantitativo}

Aqui, são apresentados conceitos sobre natureza quantitativa, nível descritivo, processo de coleta de dados através de questionários, processo de coleta e análise de dados.

\subsubsection{Natureza: quantitativa}

Segundo Pereira (2012), a análise da pesquisa quantitativa parte da abordagem de que tudo pode ser mensurado de forma numérica, podendo-se traduzir em números, opiniões e informações para que possam ser classificadas e analisadas. Este formato requer a utilização de técnicas e recursos estatísticos como forma de mensuração e organização das informações e dados coletados.

Walliman (2015) define que a análise quantitativa lida com dados na forma de números e usa operações matemáticas para investigar suas propriedades.

Com base nas referências apresentadas, pode-se concluir que a forma quantitativa de mensurar e analisar dados coletados parte do pressuposto de que numericamente esses dados podem ser interpretados e transformados em informações dentro da análise de estudo. Essa forma de pesquisa irá se basear na estruturação de dados coletados através da pesquisa com a amostragem determinada para o estudo. 


\subsubsection{Nível descritivo}

Pereira (2012) considera que a pesquisa descritiva visa descrever características de determinada população ou fenômeno ou a relação determinada entre essas variáveis, envolvendo a utilização de técnicas padrão como a coleta de dados e observação sistemática.

Santos, Kienen e Castiñeira (2015) defendem que os fatos são observados, registrados, analisados, classificados e interpretados sem que haja a interferência do pesquisador, sendo este procedimento mais indicado quando se tem por objetivo apresentar e analisar as características de um problema. Um ponto comum nos estudos descritivos é utilizar técnicas padrão para avaliar o impacto de uma determinada ocorrência na realidade e relação entre as variáveis.

Compreende-se dessa forma, que a utilização do nível descritivo dentro da estrutura da pesquisa permite a transcrição de características levantadas de uma base de informações coletadas de uma amostra previamente determinada. Na descrição desses dados será permitido comparar e estruturar uma linha de pensamento que retrate a realidade do comportamento de consumidor e como esse comportamento reflete outras estruturas de compra, como a organização do comércio e as perspectivas do mesmo.

\subsubsection{Estratégia survey}

No ponto de vista de Michel (2009), surveyé um método que utiliza escalas de medidas com a intenção de medir e quantificar opiniões e atitudes contemplando uma amostragem da população, não sendo considerada a totalidade da população. A palavra propriamente dita refere-se à ideia de levantamento, sondagem ou varredura ressaltando a sua importância na medição de atitudes, motivos e opiniões do grupo de pessoas que será definido na amostra, medindo-se as variáveis e posteriormente a associação entre elas.

Consoante a isso, Gil (2008) complementa que esse modelo de pesquisa se caracteriza pela interrogação direta aos participantes da amostragem que se deseja compreender o comportamento. Costuma-se solicitar informações a esse grupo sobre o problema a ser estudado para posteriormente através da análise quantitativa, obter conclusões aos dados coletados.

Nota-se que essa sistemática de análise consegue relatar, muito embora representada por uma amostragem, um padrão de comportamento que levará a informações consistentes da intenção de estudo que esse trabalho se propõe a apresentar, permitindo que essas informações sejam válidas para os próprios participantes, bem como para os empresários e donos de loja, que poderão valer-se dessa abordagem para analisar e compreender se sua estratégia de trabalho está condizente com o esperado pela população.

\subsubsection{Participantes do estudo}

Os participantes desse estudo são pessoas que residem em Nova Prata, com o intuito de compreender seu comportamento de compra dentro das dimensões da escolha de lojas físicas e virtuais e sua percepção sobre ambas. A amostra se deu a partir da maior quantidade possível de pessoas que se disponibilizaram a responder o questionamento desde que tivessem mais de 14 anos de idade e residissem em Nova Prata no momento da resposta ao questionário.

\subsubsection{Processo de coleta de dados}

Para a coleta de dados dessa amostragem, foi distribuído um questionário não identificado, de forma impressa e virtual, estruturado com dezenove questões de múltipla escolha que permitiram a identificação das características de cada entrevistado, bem como perguntas voltadas as suas preferências de consumo.

\subsubsection{Processo de análise de dados}

Após o recolhimento das pesquisas respondidas, os dados foram analisados quantitativamente, utilizando o nível descritivo e estratégia survey com a elaboração de tabelas e transcrição de apontamentos. Os resultados serão observados e elaborados agrupamentos de respostas que permitirão estruturar os dados. 
Por fim, os resultados obtidos através das aplicações das duas naturezas de pesquisas servirão como embasamento para as empresas-alvos poderem, se assim for de interesse, fazer-se valer de tais informações como referência, permitindo dessa forma poderem reestruturar-se dentro da composição do cenário atual apresentado.

\section{RESULTADOS DA PESQUISA}

O perfil básico dos respondentes da pesquisa, que efetuam compras físicas e virtuais mediante a apresentação dos gráficos, é o seguinte:

a) Com relação ao sexo o perfil resultou em: $59 \%$ do sexo feminino, $41 \%$ do sexo masculino, interpretando nesse cenário que o perfil de público feminino é o maior representante dessa análise;

b) As idades relacionadas resultaram em: $7 \%$ de 14 a 18 anos, $24 \%$ de 19 a 24 anos, $26 \%$ de 25 a 30 anos, $32 \%$ de 31 a 40 anos, $8 \%$ de 41 a 50 anos, $2 \%$ de 51 a 60 anos e apenas $1 \%$ acima de 60 anos. Representando dessa forma que a população entre 31 a 40 anos é a maioria dos consumidores dessa análise, seguidos pelas pessoas de 25 a 30 anos;

c) O perfil das profissões nessa pesquisa está representado por: $1 \%$ é aposentado, $2 \%$ estudantes, $3 \%$ não trabalha atualmente, $4 \%$ são autônomos, $5 \%$ professores, $7 \%$ são lojistas /vendedores, $8 \%$ por empresários, $9 \%$ estudantes, $16 \%$ representados por outras profissões não relacionadas no escopo do questionário aplicado e $45 \%$ trabalham na indústria, sendo esta, a profissão com maior representação na análise do perfil dos consumidores novapratenses;

d) O perfil, com relação ao estado civil, é: $2 \%$ divorciados, $39 \%$ solteiros e de $59 \%$ casados;

e) A análise da escolaridade se dá por: $17 \%$ dos entrevistados com pós-graduação, $19 \%$ com ensino médio, 30\% com superior incompleto e $34 \%$ com superior completo, sendo estes o perfil mais significativo desta análise;

f) A renda familiar média mensal se definiu por: $9 \%$ acima de nove salários mínimos, $20 \%$ de 7 a 9 salários mínimos, $26 \%$ de 1 a 3 salários mínimos e $45 \%$ com renda de 4 a 6 salários mínimos, sendo esta faixa, a com maior expressão de resultados na análise do perfil dos consumidores nova-pratenses.

Após a apresentação dos resultados e análise de cada indicativo dos parâmetros de respostas, pode-se concluir que o perfil do consumidor que reside em Nova Prata, que efetua compras físicas e virtuais, com base nos respondentes dessa amostragem deu-se por consumidores do sexo feminino, com idade entre trinta e um a quarenta anos, trabalhadores da indústria, casados, possuidores de formação superior completa e com renda familiar média mensal de quatro a seis salários mínimos. inferências:

A partir da análise geral dos resultados da aplicação dos questionários, foi possível chegar às seguintes

a) Os produtos que mais são adquiridos pelos consumidores no comércio físico, por ordem crescente de preferência são: livros e artigos de escritório com apenas um voto, equipamentos eletrônicos com 10 votos, móveis e utensílios domésticos com 29 votos, produtos de boutique e farmacêutico com 32 votos, vestuário e acessórios com 90 votos e alimentos e bebidas com 104 votos;

b) Os produtos que mais são adquiridos pelos consumidores no comércio virtual por ordem crescente de preferência são: alimentos e bebidas com 3 votos, produtos de boutique e farmacêutico com 10 votos, livros e artigos de escritório com 25 votos, móveis e utensílios domésticos com 32 votos, vestuário e acessórios com 74 votos e, por fim, equipamentos eletrônicos com 94 votos.

Em decorrência desses resultados pode-se perceber a inversão de preferências de consumo entre os comércios físicos e virtuais, o comércio físico tem como principais e mais relevantes apontamentos as compras de alimentos e bebidas e artigos de vestuários e acessórios, já no comércio eletrônico prevalece os equipamentos eletrônicos e também em sequência artigos de vestuário e acessórios.

Aqui estão os principais motivos que levam o consumidor que reside em Nova Prata a adquirir produtos no comércio físico e virtual:

a) O que mais é levado em consideração pelo consumidor no momento da decisão de compra no comércio físico é: a diversidade com seis votos, a própria tradição de ir às compras com 13 votos, o atendimento dos vendedores com 15 votos, a tradição e fidelidade ao comércio com 17 votos, as facilidades e condições de pagamento com 18 votos, o preço com 50 votos, a possibilidade de sair do comércio com o produto com 62 votos e, por fim, ter maior contato com o produto com 87 votos;

b) Quanto à promoção, as mais levadas em consideração são no comércio físico: sorteios e brindes com 17 votos, possuir maior prazo para pagamento com 28 votos, o pagamento parcelado e sem juros com 70 votos e os descontos como sendo a principal promoção considerada pelos compradores com 115 votos;

c) As principais formas de pagamento apontadas nas lojas da cidade, segundo a pesquisa foram: boleto bancário com quatro votos, o cartão de débito com 11 votos, o crediário oferecido pela própria loja com 40 votos, dinheiro com 46 votos e o uso do cartão de crédito com 47 votos;

d) A finalização dos pagamentos, no comércio físico, obteve resultados muito próximos, sendo $49 \%$ com a preferência do pagamento a vista e $51 \%$ com pagamento a prazo. 
e) O que mais é levado em consideração pelo consumidor no momento da decisão de compra no comércio virtual é: maior prazo para pagamento com quatro votos, o autoatendimento e o pouco tempo para frequentar o comércio local ambos 16 votos cada, as facilidades e condições de pagamento com 31 votos, a diversidade de produtos com 57 votos e, de forma disparada, o preço com 123 votos.

f) Foram apontados como fatores que reduzem a confiança das compras na loja virtual: a entrega e os prazos de entrega com 31 votos, a confiabilidade de dados com 47 votos, o receio quanto à qualidade e definições do produto com 79 votos e, o mais indicativo, o medo de fraudes por sites falsos com 87 votos.

g) Quanto à promoção no e-commerce, as mais levadas em consideração ficaram: sorteios e brindes com um voto, maior prazo para pagamento com seis votos, pagamento parcelado e sem juros com 50 votos, a opção de possuir o frete grátis com 90 votos e os descontos com 106 votos.

h) As principais formas de pagamento apontadas no questionário levantaram uma preferência pela utilização do cartão de crédito com $68 \%$ dos votos e $32 \%$ para a utilização do boleto bancário.

i) A finalização dos pagamentos, nas lojas do comércio eletrônico, semelhante às lojas da cidade também indicou pouca variação nas preferências, sendo $54 \%$ para compras a prazo e $46 \%$ para compras à vista.

Deste modo, pode-se concluir que os principais motivos considerados pelos compradores no momento de efetuarem compras de forma física é a possibilidade de ter maior contato e sair do comércio com o produto, tendo contribuído para tal preferência as promoções e os pagamentos parcelados e sem juros.

Quanto às formas de pagamento houve o indicativo da utilização do cartão de crédito e dinheiro como sendo as principais formas adotas pelos consumidores.

Já para o e-commerce, os principais motivos considerados são os preços diferenciados e a diversidade oferecida, porém há o medo de fraudes por sites falsos e o receio quanto à qualidade e definições do produto que acabam, por conseguinte, reduzindo a confiança dos consumidores.

As promoções mais apontadas foram os descontos e a oferta de frete grátis e quanto aos pagamentos a maioria desses consumidores apontou o cartão de crédito como meio principal de pagamento e a preferência por pagar suas compras a prazo.

Serão apresentados e tratados nesse momento, o resultado tabulados a partir do questionário aplicado, que servirão como indicativos para os lojistas de Nova Prata sobre apontamentos e percepções dos consumidores, também poderão ser referências para a condução de suas estratégias de negócio ou orientar suas percepções sobre as preferências e interesses de seus clientes a fim de poder mantê-los e atraí-los para seus negócios.

Assim, a tabela 1 apresenta o hábito de frequentar comércio físico para após comprar on-line

Tabela 1 - Hábito de frequentar comércio físico para após comprar on-line

\begin{tabular}{l|c}
\hline $\begin{array}{l}\text { Costuma frequentar as lojas físicas para conhecer e provar o produto para após efetuar a } \\
\text { compra na loja virtual (internet)? }\end{array}$ & Total \\
\hline Sim & 46 \\
\hline Não & 85 \\
\hline & 131 \\
\hline
\end{tabular}

Fonte: Elaborada pelas autoras (2017).

Neste apontamento foi levado em consideração o hábito de o consumidor frequentar o comércio local para conhecer e provar o produto para após efetuar a compra na loja virtual, obtendo como resultado a indicação de que $35 \%$ dos respondentes costumam visitar e $65 \%$ não costumam. Esse comportamento pode ser embasado pela própria indicação da diversidade e pelo preço, fatores, os quais, mais foram levados em conta quando optaram pelas compras nas lojas disponíveis na internet.

A tabela 2 coloca a divulgação de produtos em ferramentas virtuais.

Tabela 2 - Divulgação de produtos em ferramentas virtuais

\begin{tabular}{l|c}
\hline $\begin{array}{l}\text { Costuma visualizar a divulgação de produtos e serviços em ferramentas virtuais, qual a } \\
\text { principal? Assinale apenas uma opção. }\end{array}$ & Total \\
\hline Páginas no Facebook & 43 \\
\hline Grupo no Whatsapp & 1 \\
\hline Perfis no Instagram & 1 \\
\hline E-mail marketing & 22 \\
\hline Anúncios em páginas na internet & 64 \\
\hline
\end{tabular}

Fonte: Elaborada pelas autoras (2017). 
A divulgação de produtos a partir da utilização de ferramentas virtuais apontou uma preferência pela visualização em páginas da internete pelo aplicativo do Facebook, dessa forma sugere-se que, na medida do possível, os lojistas direcionem suas publicações por esses meios para que consigam atingir quantidades mais significativas de público que estará recebendo seus anúncios.

A tabela 3, discorre sobre a divulgação de produtos em ferramentas não virtuais

Tabela 3 - Divulgação de produtos em ferramentas não virtuais

\begin{tabular}{l|c}
\hline $\begin{array}{l}\text { Costuma visualizar a divulgação de produtos e serviços em meios NÃO virtuais, qual a } \\
\text { principal? Assinale apenas uma opção. }\end{array}$ & Total \\
\hline Anúncios no jornal & 3 \\
\hline Carros de som & 1 \\
\hline Panfletos & 55 \\
\hline Divulgação boca a boca & 39 \\
\hline Não costuma & 50 \\
\hline & 148 \\
\hline
\end{tabular}

Fonte: Elaborada pelas autoras (2017).

Com relação à divulgação em ferramentas não virtuais houve o indicativo de maior preferência a utilização de panfletos e pela divulgação boca a boca, no entanto, significativamente também foi apontado não ser um costume acompanhar os anúncios de produtos e serviços em ferramentas não tecnológicas, dentro das limitações desta amostragem, recomendando-se assim que os lojistas pudessem atentar a outras técnicas que pudessem lhe oferecer melhores respostas a suas expectativas. No que diz respeito ao marketing adotado como ferramenta de propaganda de seus produtos e serviços, sugere-se que possam fazer uso desses dados a fim de direcionar sua estratégia de comunicação com a intenção de poder alcançar um maior número de pessoas e, por conseguinte atingir aumento na disseminação da sua empresa, marca e resultados.

Aqui está a preferência sobre o tipo de comércio: virtual ou físico.

Tabela 4 - Preferência sobre tipo de comércio

\begin{tabular}{l|c}
\hline Como conclusão, sua decisão de compra preferencial é? & Total \\
\hline Loja virtual (internet) & 68 \\
\hline Comércio físico (Lojas da Cidade) & 80 \\
\hline & 148 \\
\hline
\end{tabular}

Fonte: Elaborada pelas autoras (2017).

$\mathrm{Na}$ questão sobre a decisão preferencial de compra, o resultado apontou, com pouca disparidade, preferência de $54 \%$ pelas lojas da cidade em relação a $46 \%$ para lojas da internet. Com base na sequência de indicativos sobre fatores e promoções favoráveis e desfavoráveis oferecidas em cada tipo de comércio.

Assim, aconselha-se aos lojistas da cidade de Nova Prata de uma forma geral, que tomem como base esta análise utilizando-a como ferramenta para se aproximarem mais de seus compradores, conhecer melhor seus interesses e preferências, podendo, dessa forma, atrai-los e aproximá-los de seus estabelecimentos.

\section{CONSIDERAÇÕES FINAIS}

Nesse capítulo, serão apresentadas as conclusões obtidas após o desenvolvimento desse trabalho mediante a compilação na matriz SWOT com as entrevistas com as empresas participantes do estudo, e os resultados dos dados resultantes dos questionários aplicados à amostragem da população de Nova Prata/RS.

Em primeiro momento será feita a exposição sobre os apontamentos da Empresa A. Os pontos fortes identificados estão relacionados com possuir canal físico e virtual na mesma empresa e a oferta de uma grande variedade de produtos e marcas; em contrapartida os pontos fracos apontam a variação de preço entre o canal físico e virtual e a alta rotatividade de funcionários no comércio físico. Na apresentação dos pontos críticos houve o apontamento para que houvesse a análise de reestruturar gastos e despesas da empresa em contraste com a variação de preço entre o canal físico e virtual. 
Quando questionados os consumidores sobre o que mais levavam em consideração no momento da decisão de compra no comércio físico, o atendimento dos vendedores ficou entre os três últimos relacionados pelos consumidores, apontando que atentam mais a outros fatores como ter maior contato com o produto e sair do comércio com este.

Com relação à divergência de valores entre os dois canais de venda oferecidos pela loja, nota-se que no canal virtual o mesmo produto, por vezes, possui preço mais acessível do que o comércio físico, considerando assim que este fato ocorra em virtude das necessidades de se manter uma estrutura e adequações de um espaço físico, não presentes no outro canal. No entanto, se for compilado justamente com a empresa possuir os dois canais de venda, se torna uma estratégia de negócio, a qual pode acabar deixando de vender por um meio, mas efetivado em outro, sendo que pelo canal virtual, oferecendo este melhores preços aos clientes, estará indo ao encontro com suas expectativas, pois este fator foi o mais apontado no momento de efetuar uma compra on-line. Outro ponto forte mencionado foi a grande variedade de produtos e marcas, que cruzado com as preferências identificadas na pesquisa é a segunda para o comércio virtual e última para o físico.

Conclui-se nesta empresa que embora haja condições que requeiram atenção, grande parte de sua articulação de trabalho está alinhada com a realidade do comportamento dos consumidores representando hoje um exemplo de negócio para a cidade de Nova Prata/RS.

No que compete à Empresa B, os pontos fortes apontados foram os relacionamentos estratégicos e a oferta de grande diversidade de produtos e fracos o espaço restrito para exposição de produtos na loja e a concorrência desleal. O ponto crítico desta empresa indicou a disponibilidade de mais variedades e preços mais acessíveis no comércio eletrônico alternativamente à concorrência desleal.

Os relacionamentos estratégicos apontados como sendo pontos fortes da empresa são muito importantes para ela, pois tratam de parcerias com clientes de longa data e estes mantêm uma proximidade interessante e vantajosa para a empresa. Os pontos fracos exigem maior atenção, tratam primeiramente sobre o espaço reduzido que não vêm afetando a oferta, mas acabam limitando o ambiente ao consumidor. A concorrência desleal decorre devido ao fato de haver um grande número de lojas na cidade que oferecem similarmente os mesmos produtos, sendo que a disputa de vantagens entre as mesmas acaba ganhando a preferência dos consumidores em detrimento ao crescimento da empresa.

A partir da perspectiva dos questionários, reforça-se que as preferências mais observadas nas compras online são o preço e a diversidade e para o comércio da cidade fortemente indicado o preço também como sendo relevante, precisando observar juntamente com o ponto crítico da matriz SWOTque aponta a disponibilidade de mais variedades e com preços mais acessíveis no comércio virtual e a concorrência desleal.

Para a Empresa B, levar em consideração esta percepção do consumidor se torna estrategicamente importante, pois indica que muitos de seus consumidores podem estar deixando de comprar em seu estabelecimento para optar por outro comércio que ofereça vantagens mais oportunas a seus interesses. Indica-se a possibilidade de analisar produtos semelhantes e sua estrutura interna a fim de poder encontrar situações que poderão ajustar para oferecer melhores condições e poder aumentar sua capacidade de vendas.

Na Empresa C, a oferta de produtos exclusivos e de qualidade para a cidade e a localização privilegiada foram considerados pontos fortes, já os pontos fracos foram o atendimento apenas para um nicho de mercado e o alto preço para seus produtos. Este estabelecimento comercial oferece diferencial sendo justamente seu ponto forte, a oferta de produtos exclusivos para a cidade, embora estes possuam preços mais elevados equiparados a outros de outros comércios; a escolha pode ser embasada pela qualidade ou pela exclusividade, sendo nichos de segmentação levados em consideração pelos clientes.

Os pontos fracos apresentam o fato de atender apenas clientes do sexo feminino, deixando de ofertar produtos para outros segmentos que poderiam permitir seu aumento de lucratividade, mas na relação alto preço, também de encontro com o ponto crítico da matriz SWOT que abordava o fato de disponibilidade e preços mais acessíveis no comércio eletrônico paralelo novamente a preços maiores para seus produtos, embora modelos alternativos possam ser buscados em outros estabelecimentos ou no comércio eletrônico com valores mais acessíveis, se justificam para aqueles que buscam justamente o diferencial oferecido pelas marcas e pela qualidade oferecida pelas mesmas.

Tendo em consideração as indicações realizadas percebe-se que o segmento da Empresa $C$ é direcionado para atender públicos e estratégias específicas, embora haja considerações de que o comportamento do consumidor oriente para outras preferências conforme já apontado no decorrer da pesquisa.

Obteve-se como resultado dessa pesquisa a identificação do perfil, quais produtos e o que leva o consumidor a adquiri-los de forma física e/ou virtual ao encontro do que se pretendia no início desse estudo. Além desses 
resultados foi possível compreender fatores, como: formas usuais de pagamento, métodos usuais de divulgação de marketing, exposição do fato, de frequentar o comércio local para após efetuar compras no comércio eletrônico e a decisão preferencial de compra. Todos os indicadores encontrados a partir da pesquisa puderam apresentar relevantes informações para os comerciantes da cidade, além de poder comprovar que a disseminação da tecnologia e da informação está cada vez mais presente na vida da população de cidades menores. O preço foi indicado fortemente pelos consumidores, podendo-se dessa forma considerar inclusive o momento econômico que vivemos em nosso país que deixa o povo cauteloso com seu orçamento familiar. O comércio físico apresentou de forma incisiva, alimentos e bebidas, sendo compreensível este resultado pelas necessidades diárias da população por tais produtos, permitindo que deixassem para o outro comércio produtos que poderiam esperar para possui-los, fazendo relação por levarem em consideração sair com o produto em mãos, forte resultado apontado nas preferências no comércio físico.

Finalmente, se conseguiu concluir que, embora com resultados muito próximos, a preferência do consumidor nova-pratense, dentro dos limites da pesquisa, é realizar suas compras no comércio físico. Muito embora esse resultado mostre aos empresários da cidade não ser uma situação de total conforto, reforçando o exposto no capítulo seis quando tratava que ambos os comércios possuem suas vantagens, no entanto o comércio eletrônico permite abranger mais mercados consumidores, possui menos custos na operação que afetam diretamente os preços e amplia significativamente o tempo para atendimento, pois não leva em conta o horário de atendimento, fato que ocorre na loja física.

Não haverá a substituição da loja tradicional, mas mediante a grande proximidade de preferências, é de grande valia considerar adotar ambas as formas de comércio, quando possível, para que alcancem maiores resultados organizacionais.

Reconhece-se nessa análise um fato importante e interessante, das cento e quarenta e oito pessoas que responderam ao questionário, apenas dezessete não possuem o hábito de efetuarem compras no comércio virtual, representando apenas $11 \%$ do total apresentado. Esses são representados por pessoas de ambos os gêneros, com variadas faixas etárias e rendas, indicativo que reforça a difusão da tecnologia e aproximação dos mercados na vida dos consumidores.

Sugere-se que sejam desenvolvidas na cidade de Nova Prata, futuras pesquisas que permitam realizar análises de estratégias de marketing e vendas para que os empresários lojistas possam adotá-las para atingirem resultados mais sólidos e construtivos, apoiados pelos dados apontados nessa apresentação. Outra sugestão é a Câmara de Dirigentes e Lojistas viabilizar pesquisas de mercado na cidade que possam indicar a seus associados, diferentes informações importantes que possam gerar parâmetros sobre preferências e tendências e, assim poderem antever e planejarem ações que vão de encontro às esperadas por seus clientes finais, a população.

\section{REFERÊNCIAS}

COOPER, Donald R; SCHINDLER, Pamela S. Métodos de Pesquisa em Administração. 10. ed. Porto Alegre: Bookman, 2011.

DE ANGELO, F. Claudio; GIANGRANDE, Vera. Marketing de relacionamento no varejo. São Paulo: Saint Paul Editora. 2007.

GIL, Antonio Carlos. Métodos e técnicas de pesquisa social. 6. ed. São Paulo: Atlas, 2008.

GIL, Antonio Carlos. Como elaborar projetos de pesquisa. 5. ed. São Paulo: Atlas, 2010.

HAIR JUNIOR, F. et al. Análise multivariada de dados. 5. ed. Porto Alegre: Bookman, 2005.

HAWKINS, Del. I; MOTHERSBAUGH, David. L; BEST, Roger. J. Comportamento do Consumidor: construindo a estratégia de marketing. 10. ed. Rio de Janeiro: Elsevier, 2007.

MARCONI. M. A.; LAKATOS, E. M. Técnicas de pesquisa. São Paulo: Atlas, 1999.

MICHEL, Helena M. Metodologia e pesquisa científica em ciências sociais. 2. ed. São Paulo: Atlas. 2009. 
MOURA, Amauri. Diferenças e semelhanças do comércio físico e virtual. 2014. Disponível em:

$<$ https://www.ecommercebrasil.com.br/artigos/diferencas-e-semelhancas-comercio-fisico-e-virtual/>. Acesso em 06 abr. 2016.

PEREIRA, M. José. Manual de metodologia da pesquisa científica. 3. ed. São Paulo: Atlas, 2012.

PETER, J. Paul; OLSON, C. Jarry. Comportamento do Consumidor e estratégia de marketing. 8. ed. Porto Alegre: AMGH, 2010.

ROCHA, Lygia Carvalho. Consumidor: Como Elaborar o seu Perfil. Rio de Janeiro: LTC, 2009.

ROESCH, Sylvia Maria Azevedo. Projetos de estágio e de pesquisa em administração: guia para estágios, trabalhos de conclusão, dissertações e estudos de caso. 3. ed. São Paulo: Atlas, 2005.

SANTOS, Pedro Antônio dos; KIENEN, Nádia; CASTIÑEIRA Maria Inês. Metodologia da Pesquisa Social: Da proposição de um problema à redação e apresentação do relatório. São Paulo: Atlas, 2015.

SCHWERINER, Mario René. Comportamento do Consumidor. São Paulo: Saraiva, 2006.

SOLOMON, Michael. R. O comportamento do consumidor: comprando, possuindo e sendo. 9. ed. Porto Alegre: Bookman, 2011.

TEIXEIRA, Tarcísio. Comércio Eletrônico: conforme o marco civil da internete a regulamentação do e-commerce no Brasil. São Paulo: Saraiva, 2015.

TURBAN, Efraim; KING, David. Comércio eletrônico: estratégia e gestão. São Paulo: Pearson Prentice Hall, 2004.

WALLIMAN, Nicholas. Métodos de Pesquisa. Tradução: Arlete Simille Marques. São Paulo: Saraiva, 2015. 